\title{
Dynamic shadowing growth and its energy applications
}

\author{
Yiping Zhao* \\ Department of Physics and Astronomy, Nanoscale Science and Engineering Center, The University of Georgia, Athens, GA, USA
}

\section{Edited by:}

Bingqing Wei, University of Delaware, USA

\section{Reviewed by:}

Davide Mariotti, University of Ulster, UK

Zhifeng Huang, Hong Kong Baptist University, China

\section{*Correspondence:}

Yiping Zhao, Department of Physics and Astronomy, Nanoscale Science and Engineering Center, The

University of Georgia, 220 Riverbend

Road, Athens, GA 30602, USA

e-mail: zhaoy@physast.uga.edu
The unique features of dynamic shadowing growth (DSG) in structural and compositional design of nanomaterials are discussed. Their recent applications in energy storage, fuel cell, and solar energy conversion have been reviewed briefly. Future directions for applying DSG nanostructures in renewable energy applications are presented.

Keywords: dynamic shadowing growth, glancing angle deposition, super capacitor, hydrogen storage, $\mathrm{Li}^{+}$battery, fuel cell, photovoltaics, solar water splitting
Dynamic shadowing growth (DSG) or glancing angle deposition (GLAD) is a versatile nanofabrication technique based on the self-shadowing effect during a thin-film deposition process (Young and Kowal, 1959; Motohiro and Taga, 1989; Robbie and Brett, 1997; Robbie et al., 1998; Messier et al., 2000; He and Zhao, 2011). For a conventional physical vapor or chemical vapor thinfilm deposition process, as long as the incident vapor possesses certain directionality and there are protrusions (shadowing centers) on the substrate, as shown in Figure 1A, a self-shadowing effect will occur, i.e., there will be an area around the protrusion opposite to the incident vapor direction that cannot receive vapor to grow further. This will cause a preferred growth of the protrusion toward the vapor incident direction. There are several consequences resulting from this self-shadowing effect. First, film growth front that is dominated by the self-shadowing effect is unstable, which results in overhangs on the substrate (Lichter and Chen, 1986; Roland and Guo, 1991; Krug and Meakin, 1993; Yao and Guo, 1993; Drotar et al., 2000). This induces preferred growth of taller surface features and generates large roughness or nanostructures. Second, the growth is site specific, i.e., preferred growth mostly occurs on the locations of protrusions. Finally, the growth is asymmetric, i.e., only one side of the protrusions receives the incoming vapors to continue the growth.

Any conventional thin-film deposition technique could naturally exhibit the self-shadowing effect due to the uneven surface features formed thermodynamically during deposition and the directionality of the local incident vapor. However, in order for the self-shadowing effect to be the dominant growth mechanism, highly directional vapor is required and surface smoothening effects such as surface diffusion should be limited. Many physical vapor deposition methods working in high vacuum or ultrahigh vacuum, such as thermal evaporation (Beydaghyan et al., 2008), electron beam evaporation (Zhao et al., 2002a,b), and molecular beam epitaxy (Robbie et al., 2004), can be used to generate pronounced self-shadowing effects due to the intrinsic directionality occurring at long vapor striking distances. Other low vacuum deposition techniques, such as sputtering growth (Sit et al., 1999; Lintymer et al., 2003; Zhou and Gall, 2006), pulsed laser deposition (Vick et al., 1999), and chemical vapor deposition (Ma et al., 2010a), can also produce significant self-shadowing effects if the depositing vapor beam is properly arranged, i.e., a collimator can be used to direct the growth vapor.

Once the self-shadowing effect becomes the dominant growth mechanism, by combining substrate rotation together with different thin-film growth configurations, such as multilayer deposition and co-deposition, one can alter the direction of the incident vapor with respect to the shadowing centers to generate nanostructures with different morphology and composition. Specifically, the polar angle $\theta$ between surface normal of the substrate and the vapor direction and the azimuthal angle $\varphi$ in the substrate plane (Figure 1B) can be dynamically programed to design different nanostructures. Compared to other nanofabrication and synthesis techniques, DSG offers the following unique features (Robbie and Brett, 1997; Zhao et al., 2003; He et al., 2007a,b, 2008b,c, 2010; Steele and Brett, 2007; Zhou et al., 2008; He and Zhao, 2009a; Smith and Zhao, 2009).

\section{MORPHOLOGICAL SCULPTURE}

To use the self-shadowing effect to produce well-separated nanorod arrays, the angle $\theta$ should be larger than $70^{\circ}$ (Robbie and Brett, 1997; Zhao et al., 2003; He et al., 2007a,b, 2008b,c, 2010; Steele and Brett, 2007; Zhou et al., 2008; He and Zhao, 2009a; Smith and Zhao, 2009). By programing the locations and motions of both angles $\theta$ and $\varphi$, nanorods of different morphology can be formed as shown in Figures 2A-F. The simplest morphology is the tilted nanorod array (Figure $\mathbf{2 A}$ ) formed by oblique-angle deposition (OAD), where $\theta\left(\geq 70^{\circ}\right)$ is fixed with no azimuthal rotation. The angle $\theta$ can be used to tune the density, the diameter, and the tilting angle of the nanorod array. Other deposition conditions such as substrate temperature can also be used to adjust the abovementioned morphological parameters, and at the same time, tune the crystallinity of the resulting nanostructures 


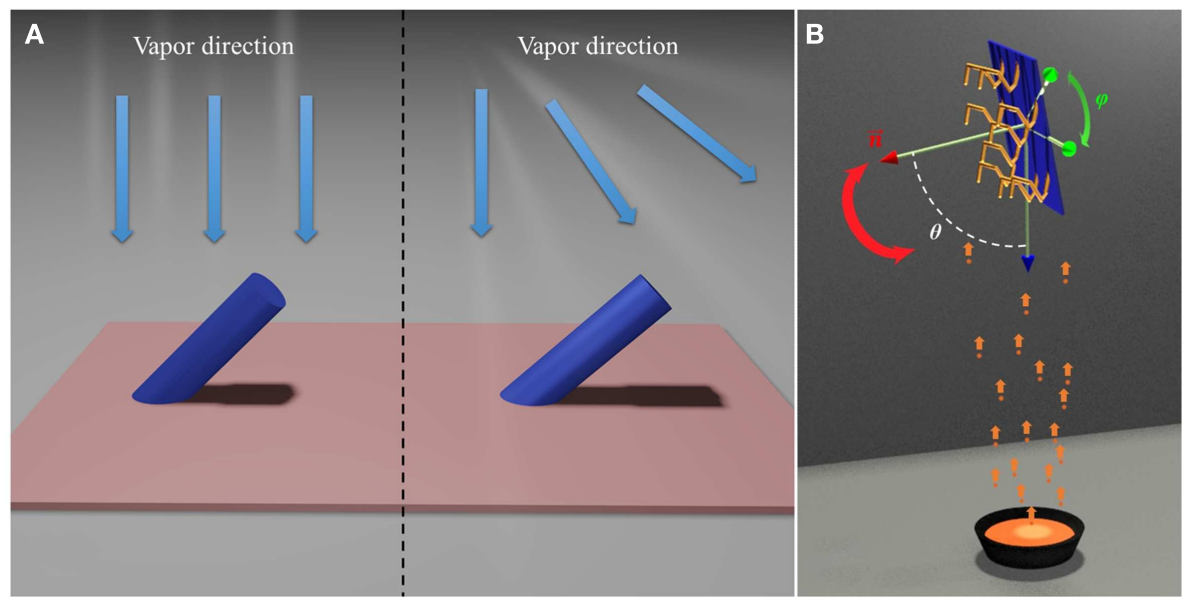

FIGURE 1 | (A) Self-shadowing effect: collimated parallel vapor beam (left) and divergent vapor beam (right). (B) The general deposition configuration of DSG.

(Schubert et al., 2006; Patzig and Rauschenbach, 2008). If $\theta\left(>70^{\circ}\right)$ is fixed, but the substrate is rotating azimuthally with a constant speed, a vertically aligned nanorod array (Figure $2 \mathrm{~B}$, at a relatively fast rotation speed) or a helical nanorod array (Figure 2C, at a very slow rotation speed) will be fabricated. For the helical structure, the pitch height, the helical diameter, and the length are determined by the rotation speed and the nanorod deposition rate. Thus, by programing the azimuthal rotation, one can generate nanorods with different morphology. For example, by periodically rotating substrate $180^{\circ}$ azimuthally and quickly after a period of OAD, zigzag nanorods can be produced (Figure 2D). The number of bends and the length of each arm are programed by the azimuthal rotation. If the fast rotation angle is set to be smaller than $180^{\circ}$, such as $120^{\circ}$ and $90^{\circ}$, polygonal helices can be constructed. Similarly, one can also program the rotation of the polar angle $\theta$ to create the zigzag nanorods; after a period of $\mathrm{OAD}, \theta$ can be quickly rotated to $-\theta$ (i.e., the surface normal in Figure 1B changes to its mirror location with respect to the incident vapor direction). If the $\theta$ angle is programed to move periodically in between $\theta_{\min }$ and $\theta_{\max }\left(0<\theta_{\min }<\theta_{\max }<90^{\circ}\right)$, a $C$-shape nanorod array (Figure 2E) or a bead-like nanorod array (Figure 2F) can be designed, depending on the rotation speed and deposition rate. The idea of programing the angular rotations can be extended to produce periodic structures with morphological modulation, such as helical-straight nanorod structures, or zigzag-straight rod structure. If a regular two-dimensional template is provided as a substrate, then the site-specified growth of the self-shadowing effect can ensure the fabrication of a regularly aligned nanorod array. Thus, the beauty of the DSG (GLAD) fabrication technique lies in that all the structural parameters of three-dimensional nanorod arrays can be controlled by computer programming, which is unique compared to other nanofabrication techniques.

\section{HETERO-NANOSTRUCTURE DESIGN}

The advantage of morphological sculpture can be combined with conventional thin-film multilayer deposition technique to design different heterostructured nanorods with tunable morphology. A natural extension for structures in Figures $2 \mathrm{~A}-\mathbf{F}$ is to add a layer of nanorod with different material but similar morphology. One example is shown in Figure 2G, the multilayered heteronanorods can be easily fabricated by keeping the same rotation program while alternating the deposition material. Such multilayered nanorod structures, like straight nanorods, zigzag nanorods, and helical structures, have been realized by different research groups (He and Zhao, 2011). In addition to the multilayered heterostructures, side-coated structures are possible if one utilizes the asymmetric deposition feature of the self-shadowing effect. In this case, the aligned nanorod array itself can serve as a substrate, and the angle between the surface normal of the nanorod side surface and the vapor incident direction determines the shadowing effect. By fixing $\theta$ at a relatively small angle $\left(<40^{\circ}\right)$, an additional layer of different material can be deposited on one side of the vertical nanorods (Figure $\mathbf{2} \mathbf{H}$ ). The coverage or the length of the coating is determined by $\theta$ and the separation among adjacent nanorods. If during the deposition, the polar angle is programed to swing between $\theta$ and $-\theta$ periodically while there is no azimuthal rotation, sandwiched nanorods shown in Figure 2I can be created. However, if the azimuthal angle is programed to rotate continuously for the second layer deposition while keeping $\theta$ fixed, core-shell nanorods (Figure 2J) will be fabricated. The thickness of the shell is determined by the growth rate, the angle $\theta$, and the deposition time. If the angles $\theta$ and $\varphi$ as well as multilayer deposition can be programed simultaneously, complicated heterostructures like checkerboard structure can be fabricated as shown in Figure 2K. This can be realized by first creating a side-coated nanorod array (Figure $2 \mathbf{H}$ ), then depositing side-coated nanorods by making sure that there is a $180^{\circ}$ phase shift in $\varphi$ direction during the second deposition. Repeating the procedure will give a multilayered structure. Furthermore, with the advantage of morphological sculpture, the heterostructures one can design using DSG are not limited to straight nanorods shown in Figures 2G-K. Three-dimensional nanostructures can also be created. Finally, DSG can be combined 


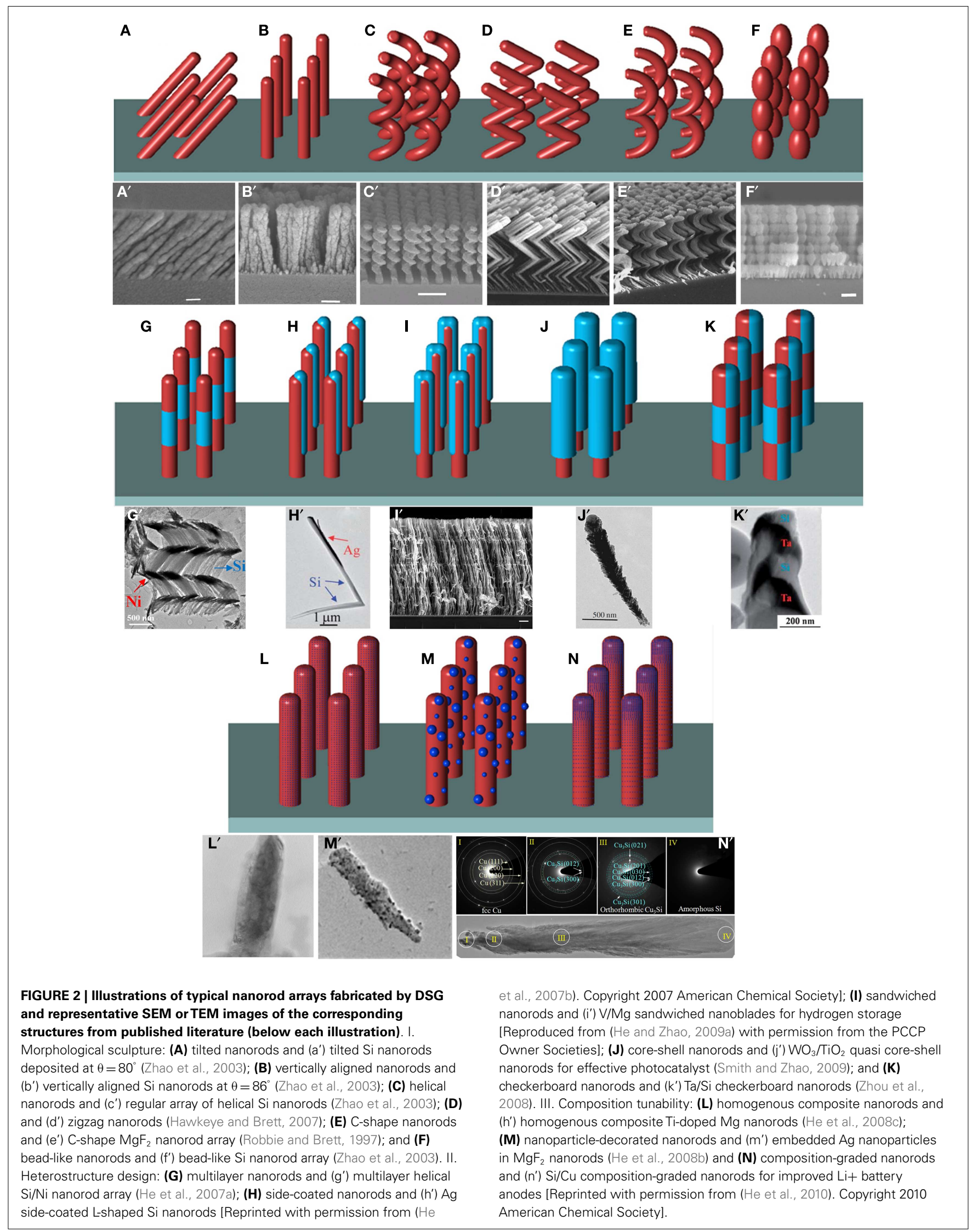


with other nanofabrication techniques to develop many unique material systems.

\section{COMPOSITION TUNABILITY}

From a materials science point of view, conventional thin-film deposition techniques not only can generate thin films with single components or single compounds but composite thin films can also be produced if two or more sources are simultaneously used during the deposition. Therefore, the combination of codeposition configuration with the DSG principle can be used to design composite nanorod arrays (He and Zhao, 2011). Based on the physical and chemical properties of the two (or three, or more) materials for co-deposition, nanorod arrays with a homogenous mixture (Figure 2L) or with nanoparticle decoration (Figure 2M) can be fabricated, provided that the deposition rates of the two materials are fixed throughout the deposition process. If the ratio of the deposition rates of the two materials is programed dynamically during growth, a composition-graded nanorod array can be produced (Figure 2N). The co-deposition combined with multilayer deposition and DSG can be used to design many new nanocomposites with different layered structure and nanorod morphology.

In summary, DSG is a versatile and simple nanofabrication technique to design three-dimensional, well-aligned, and heterostructured nanorod arrays, and it has the following specific advantages:

(1) DSG naturally forms high aspect ratio aligned nanorod arrays with high surface areas and tunable layered structures.

(2) The size, separation, and density of the nanorods can be controlled by deposition conditions and templates.

(3) The shape, alignment, and orientation of the nanorods can be easily changed by programing the substrate rotation procedure.

(4) Three-dimensional nanorod structures can be sculptured by programing the rotations of the angles $\theta$ and $\varphi$.

(5) Different configurations of heterostructured nanorods can be designed.

(6) The composition of composite nanorods can be programed.

(7) There is virtually no constraint on the material that can be used for DSG, as long as the material can be evaporated and the vapor can be collimated.

(8) The process is compatible to the conventional microfabrication processes, which makes scale-up fabrication possible. In fact, the Brett group has recently demonstrated the feasibility of roll-to-roll DSG (GLAD) fabrication (Krause et al., 2013).

These advantages make DSG an excellent nanofabrication technique to design different nanomaterials for energy applications. To date, while promising results have already been demonstrated, the potential for DSG to further energy research has not been fully realized.

Due to the high surface area of DSG films and aligned nanorod arrays, energy storage applications of DSG thin films have been explored. Electrochemical performance of carbon nanostructures fabricated by DSG has been studied by the Brett group to investigate the potential application as supercapacitors (Kiema and Brett,
2004). They found that post-deposition treatment was needed to improve the electrode reactivity. The use of DSG nanostructures for hydrogen storage has been explored extensively. Early works showed that $\mathrm{LaNi}_{5}$ (Devi et al., 2001), Cr-coated TiNi (Singh et al., 2007), and $\mathrm{MmNi}_{4.5} \mathrm{Al}_{0.5}$ (Jain et al., 2000, 2008) thin films deposited by OAD at high $\theta$ angles had better hydrogen storage performance. Very recently, different groups have shown that $\mathrm{Mg}$ can form nanoblade morphology due to OAD growth, and they exhibit improved hydrogen storage thermodynamics (Tang et al., 2007; He et al., 2008a,c). Once the surface of the Mg nanoblades were decorated with catalysts such as $\mathrm{Pt}, \mathrm{Pd}$, or V, both the thermodynamics and the kinetics of the hydrogen adsorption and desorption could be improved (He and Zhao, 2009a,b; Bayca et al., 2011; Liu et al., 2011; Liu and Wang, 2012). The amount of reversible hydrogen in $\mathrm{V}$ decorated $\mathrm{Mg}$ nanoblades was found to be less than $6 \mathrm{wt} . \%$, which was slightly smaller than the theoretical value $7.6 \mathrm{wt} . \%$ of $\mathrm{MgH}_{2}$. The material could absorb hydrogen to saturation within $7 \mathrm{~min}$ at $570 \mathrm{~K}$, and desorb hydrogen almost completely within $15 \mathrm{~min}$ at $570 \mathrm{~K}$ (He and Zhao, 2009a). The absorption activation energy was estimated to be $35.0 \pm 1.2 \mathrm{~kJ} / \mathrm{mol} \mathrm{H}_{2}$ and desorption activation energy $65.0 \pm 0.3 \mathrm{~kJ} / \mathrm{mol} \mathrm{H} \mathrm{H}_{2}$. Both were much lower than the desorption energy of $141 \mathrm{~kJ} / \mathrm{mol} \mathrm{H}_{2}$ for $\mathrm{MgH}_{2}$ film (Checchetto et al., 2005) and $156 \mathrm{~kJ} / \mathrm{mol} \mathrm{H}_{2}$ for $\mathrm{MgH}_{2}$ powder (Huot et al., 1999). If the catalyst decorated nanoblades are protected by polymer (Parylene) coating through vapor deposition, air stable hydrogen storage material can be achieved (Liu et al., 2013a).

Dynamic shadowing growth has also been used to fabricate electrodes for battery applications, especially the anodes of $\mathrm{Li}^{+}$battery. Si nanorods fabricated by DSG have demonstrated $>3000 \mathrm{mAh} / \mathrm{g}$ capacity by Brett and Lu group (Fleischauer et al., 2009; Teki et al., 2009). However, silicon exhibits large volume changes (about 300\%) upon Li insertion and extraction. The stress induced by this volume change causes cracking, pulverization, and peeling of the underlying current collector, which leads to loss of electrical contact, formation of additional solid-electrolyteinterphase layer, and eventual fading of capacity. To circumvent this problem, stress compliant layer has been engineered. Lu group designed a carbon nanorod/Al capped layer to release the stress of Si nanorods during the $\mathrm{Li}^{+}$shuttling (Krishnan et al., 2011), while Zhao group used the $\mathrm{Si}-\mathrm{Cu}$ composite nanorods and $\mathrm{Si}-\mathrm{Cu}$ composition-graded nanorods to reduce the stress effect (Au et al., 2011; He et al., 2012). Recently Mullins' group showed that control oxidation of Si nanorods or $\mathrm{Si}_{1-\mathrm{x}} \mathrm{Ge}_{\mathrm{x}}$ composite nanorods could greatly improve the anode performance (Abel et al., 2012, 2013a). Other anode materials fabricated by DSG, such as Al (Au et al., 2010; Sharma et al., 2013), Ge (Abel et al., 2013b), $\mathrm{TiO}_{2}$ (Lin et al., 2011), and $\mathrm{WO}_{3}$ (Figueroa et al., 2007), have also been explored for $\mathrm{Li}^{+}$battery applications.

The porous nature of DSG thin films also has found applications as fuel cell electrodes or catalyst supporting structures. Both Gall and Karabacak groups showed that the Pt nanoparticles/nanorods fabricated by DSG could improve the oxygen reduction reaction with a high mass-specific performance (Gasda et al., 2009; Khudhayer et al., 2011). The catalytic performance of fuel electrodes was further improved by multilayer $\mathrm{Pt} / \mathrm{Ru}$ nanorods (Yoo et al., 2010) and Pt-Ni alloy nanorods (Kariuki et al., 2013). In fact, the mass-specific activity of the Pt-Ni alloy nanorods was 
found to be a factor of 2.3-3.5 higher than that of pure Pt nanorods of the same dimensions. Conductive DSG nanorods, such as $\mathrm{Ti}$ (Bonakdarpour et al., 2008), C (Gasda et al., 2010), Cr (Khudhayer et al., 2012), Ni (Francis et al., 2013), and niobium oxides (Bonakdarpour et al., 2012), were also used as catalyst supporting structures to reduce the loading of Pt in fuel cell electrodes.

The use of DSG nanostructures for solar application has been studied more extensively compared to other applications. Most works have focused on dye-sensitized solar cells (DSSC), organic solar cells (OSC), and related surface coating. For DSSC, DSGproduced $\mathrm{TiO}_{2}$ nanorods were mainly used (Kiema et al., 2005; Yang et al., 2009; Wong et al., 2010; Gonzalez-Garcia et al., 2011). An early report by Brett group showed that the annealed $\mathrm{TiO}_{2}$ nanostructures gave better performance, and a photoelectric conversion efficiency of $4.1 \%$ could be achieved (Kiema et al., 2005). Recent work by Wong et al. (2010) demonstrated a higher cell efficiency of 6.1\%. Li and Forrest (2009) reported an OSC consisted of chloroaluminum phthalocyanine $(\mathrm{ClAlPc})$ and $\mathrm{C}_{60}$ grown by $\mathrm{OAD}$, and demonstrated an efficiency of 2.0-2.8\%. Other OSCbased semiconductors such as copper phthalocyanine (CuPc) (Van Dijken et al., 2011; Yang et al., 2013), ClAlPc (Yang et al., 2013), and lead phthalocyanine ( $\mathrm{PbPc}$ ) (Liu et al., 2013b) were also made into nano-columnar structures by $\mathrm{OAD}$, and the donoracceptor hetero-junctions were characterized. Furthermore, high surface area nanorod electrodes made by DSG, such as indium tin oxide (ITO) (Yu et al., 2010; Rider et al., 2011), $\mathrm{SnO}_{2}$ :Sb (ATO) (Xiao et al., 2010), and $\mathrm{C}_{60}$ fullerene (Thomas et al., 2011, 2012), were used for OSC construction. Besides DSSC and OSC, hybrid inorganic-organic solar cells (HIOSCs) were incorporated with DSG nanostructures (Ma et al., 2010b). Using a modified hot wire chemical vapor deposition system (Guo et al., 2011) was able to grow crystalline Si nanorod array, coated with amorphous $\mathrm{Si}$ shell. After spin-coating 3-hexylthiophene (P3HT), a HIOSC with $1 \%$ conversion efficiency was achieved (Ma et al., 2010b). Similar inorganic nanorod acceptor-organic donor structures, such as $\mathrm{TiO}_{2}-\mathrm{P} 3 \mathrm{HT}$ (Gerein et al., 2010), $\mathrm{TiO}_{2}$-porphyrin (Castillero et al., 2010), and $\mathrm{ZnO}-\mathrm{InN}-\mathrm{PbPc}$ (Chen and Chen, 2012), were fabricated, but the measured conversion efficiency was less than $0.2 \%$. In addition to solar cells, DSG nanostructures were also utilized as photoelectrodes for solar water splitting. Wolcott et al. (2009) demonstrated a $0.1 \%$ photo-to-hydrogen efficiency with OAD $\mathrm{TiO}_{2}$ nanorods, and they further showed that $\mathrm{TiO}_{2}-\mathrm{WO}_{3}$ core-shell nanorods could further extend the photoconversion to visible wavelength range (Smith et al., 2011). Other $\mathrm{TiO}_{2}$-based nanostructures, such as $\mathrm{Cr}$ doped (Larsen et al., 2011) and CdSe decorated (Larsen et al., 2012) $\mathrm{TiO}_{2}$ nanorods, were explored as the photoelectrodes for water splitting. Finally, since DSG can tune the optical property of each layers, it has been used widely to create antireflection coating for solar cell application (Poxson et al., 2009, 2011), especially based on ITO nanostructure, to improve the light trapping efficiency and conversion efficiency (Chhajed et al., 2008; Yu et al., 2009; Yao et al., 2012).

Compared to materials made from other nanofabrication techniques, the nanostructures made by DSG have not been extensively studied in renewable energy area. This is due to several reasons. First, the crystallinity of the nanorod arrays fabricated by DSG is poor. In order to form the well-separated nanorod arrays during DSG process, the self-shadowing effect shall dominate the growth process while the adatom diffusion needs to be minimized. This requires the deposition occurring at lower temperature. The films grown at near room temperature are usually amorphous for most compound materials and polycrystalline for metals. For applications requiring high-quality crystalline nanostructures, post-deposition annealing is usually performed. However, the improvement in crystallinity is typically insignificant. Second, high-quality heterojunction interfaces are lacking. The low temperature grown nanorods by DSG usually have rough surfaces. Thus, the deposition of an additional layer on the rough, porous, and amorphous nanorods to generate heterostructures does not result in good-quality interface. Many defects could exist at the interface that can impair the charge transport properties. To overcome abovementioned shortcomings, the adatom diffusion has to be increased to improve the quality of the nanostructures. Recently, high temperature DSG has been explored by Suzuki et al. (2006, 2011) and Brett groups (Taschuk et al., 2013; Beaudry et al., 2014). They show vapor-liquid-solid-like growth of single crystalline nanowires with directions controlled by the incident vapor. Another alternative method is to use energetic beam-assisted deposition. It is well-known that the presence of energetic ions during conventional thin-film deposition can greatly improve the quality of the films, and sometimes can even achieve low temperature epitaxial growth (Takagi et al., 1975; Takagi, 1982; Hirvonen, 1991; Mohan and Krishna, 1995; Monteiro, 2001; Manova et al., 2010; Popok, 2011). Brett group investigated the oxide nanorod growth using ion-assisted GLAD. Under $\mathrm{Ar}^{+}$-assisted deposition ( $390 \mathrm{eV}$ and $6 \mathrm{~mA}$ with $45^{\circ}$ ion incident angle), they found that the density and tilting angle of $\mathrm{SiO}_{2}$ and $\mathrm{TiO}_{2}$ nanorods were both increased (Sorge and Brett, 2010). They also investigated the morphology of 12 different oxides and fluorides fabricated using a similar technique, and reached a similar conclusion (Sorge et al., 2012). Third, the composition of the most DSG materials studied so far is either single element or single compound, while many energy-related applications require multi-element compounds or composites. New material discovery also requires the tunability of material composition. As discussed above, co-deposition DSG has the capability to program the composition during the deposition. Some of the current studies on composite nanostructures used in battery, fuel cell, and photocatalyst have already demonstrated the advantages of complex materials or composite materials. Yet, there are not many groups that have the capability to perform codeposition DSG. In spite of these temporary drawbacks, progress is being made, and once the structure sculpture, composition design, and high-quality fabrication have been combined and integrated perfectly, the DSG technique will become an indispensable nanofabrication technique for many different energy applications.

\section{ACKNOWLEDGMENTS}

The author would like to thank Mr. Yizhuo He and Mr. Weijie Huang for plotting the figures and Mr. George Larsen for proofreading the manuscript.

\section{REFERENCES}

Abel, P. R., Chockla, A. M., Lin, Y. M., Holmberg, V. C., Harris, J. T., Korgel, B. A., et al. (2013a). Nanostructured $\mathrm{Si}(\mathrm{i}-\mathrm{x}) \mathrm{Gex}$ for tunable thin film lithium-ion battery anodes. ACS Nano 7, 2249-2257. doi:10.1021/nn3053632 
Abel, P. R., Lin, Y. M., De Souza, T., Chou, C. Y., Gupta, A., Goodenough, J. B., et al. (2013b). Nanocolumnar germanium thin films as a high-rate sodium-ion battery anode material. J. Phys. Chem. C 117, 18885-18890. doi:10.1021/jp407322k

Abel, P. R., Lin, Y. M., Celio, H., Heller, A., and Mullins, C. B. (2012). Improving the stability of nanostructured silicon thin film lithium-ion battery anodes through their controlled oxidation. ACS Nano 6, 2506-2516. doi:10.1021/nn204896n

Au, M., He, Y., Zhao, Y., Ghassemi, H., Yassar, R. S., Garcia-Diaz, B., et al. (2011). Silicon and silicon-copper composite nanorods for anodes of $\mathrm{Li}$-ion rechargeable batteries. J. Power Sources 196, 9640-9647. doi:10.1016/j.jpowsour.2011.07.022

Au, M., Mcwhorter, S., Ajo, H., Adams, T., Zhao, Y., and Gibbs, J. (2010). Free standing aluminum nanostructures as anodes for Li-ion rechargeable batteries. J. Power Sources 195, 3333-3337. doi:10.1016/j.jpowsour.2009.11.102

Bayca, S. U., Cansizoglu, M. F., Biris, A. S., Watanabe, F., and Karabacak, T. (2011). Enhanced oxidation resistance of magnesium nanorods grown by glancing angle deposition. Int. J. Hydrogen Energy 36, 5998-6004. doi:10.1016/j.ijhydene.2011. 01.152

Beaudry, A. L., Laforge, J. M., Tucker, R. T., Sorge, J. B., Adamski, N. L., Li, P., et al. (2014). Directed branch growth in aligned nanowire arrays. Nano Lett. 14, 1797-1803. doi:10.1021/nl404377v

Beydaghyan, G., Renaud, J.-L. M., Bader, G., and Ashrit, P. V. (2008). Enhanced electrochromic properties of heat treated nanostructured tungsten trioxide thin films. J. Mater. Res. 23, 274-280. doi:10.1557/jmr.2008.0037

Bonakdarpour, A., Fleischauer, M. D., Brett, M. J., and Dahn, J. R. (2008). Columnar support structures for oxygen reduction electrocatalysts prepared by glancing angle deposition. Appl. Catal. A 349, 110-115. doi:10.1016/j.apcata.2008.07.015

Bonakdarpour, A., Tucker, R. T., Fleischauer, M. D., Beckers, N. A., Brett, M. J., and Wilkinson, D. P. (2012). Nanopillar niobium oxides as support structures for oxygen reduction electrocatalysts. Electrochim. Acta 85, 492-500. doi:10.1016/j.electacta.2012.08.005

Castillero, P., Sanchez-Valencia, J. R., Cano, M., Pedrosa, J. M., Roales, J., Barranco, A., et al. (2010). Active and optically transparent tetracationic porphyrin/ $/ \mathrm{TiO}_{2} \mathrm{com}$ posite thin films. ACS Appl. Mater. Interfaces 2, 712-721. doi:10.1021/am900746q

Checchetto, R., Bazzanella, N., Miotello, A., and Mengucci, P. (2005). Deuterium storage in Mg-Nb films. J. Alloys Comp. 404, 461-464. doi:10.1016/j.jallcom. 2004.10.093

Chen, C. C., and Chen, L. C. (2012). Fabrication and characteristics of ZnO/OAD$\mathrm{InN} / \mathrm{PbPc}$ hybrid solar cells prepared by oblique-angle deposition. Molecules 17, 9496-9505. doi:10.3390/molecules17089496

Chhajed, S., Schubert, M. F., Kim, J. K., and Schubert, E. F. (2008). Nanostructured multilayer graded-index antireflection coating for Si solar cells with broadband and omnidirectional characteristics. Appl. Phys. Lett. 93, 251108-251108-3. doi: $10.1063 / 1.3050463$

Devi, B., Vashistha, M., and Jain, I. P. (2001). Hydrogen in obliquely deposited LaNi5 thin films. Int. J. Hydrogen Energy 26, 1189-1192. doi:10.1016/s0360-3199(01) 00056-8

Drotar, J. T., Zhao, Y. P., Lu, T. M., and Wang, G. C. (2000). Surface roughening in shadowing growth and etching in 2+1 dimensions. Phys. Rev. B 62, 2118-2125. doi:10.1103/PhysRevB.62.2118

Figueroa, R., Cruz, T. G. S., and Gorenstein, A. (2007). WO $\mathrm{WO}_{3}$ pillar-type and helicaltype thin film structures to be used in microbatteries. J. Power Sources 172, 422-427. doi:10.1016/j.jpowsour.2007.05.080

Fleischauer, M. D., Li, J., and Brett, M. J. (2009). Columnar thin films for threedimensional microbatteries. J. Electrochem. Soc. 156, A33-A36. doi:10.1149/1. 3006001

Francis, S. A., Tucker, R. T., Brett, M. J., and Bergens, S. H. (2013). Structural and activity comparison of self-limiting versus traditional Pt electro-depositions on nanopillar Ni films. J. Power Sources 222, 533-541. doi:10.1016/j.jpowsour.2012. 09.025

Gasda, M. D., Eisman, G. A., and Gall, D. (2010). Nanorod PEM fuel cell cathodes with controlled porosity. J. Electrochem. Soc. 157, B437-B440. doi:10.1149/ 1.3294721

Gasda, M. D., Teki, R., Lu, T. M., Koratkar, N., Eisman, G. A., and Gall, D. (2009). Sputter-deposited Pt PEM fuel cell electrodes: particles vs layers. J. Electrochem. Soc. 156, B614-B619. doi:10.1149/1.3097188

Gerein, N. J., Fleischauer, M. D., and Brett, M. J. (2010). Effect of $\mathrm{TiO}_{2}$ film porosity and thermal processing on $\mathrm{TiO}_{2}-\mathrm{P} 3 \mathrm{HT}$ hybrid materials and photovoltaic device performance. Sol. Energy Mater. Sol. Cells 94, 2343-2350. doi:10.1016/j.solmat.2010.08.010
Gonzalez-Garcia, L., Gonzalez-Valls, I., Lira-Cantu, M., Barranco, A., and GonzalezElipe, A. R. (2011). Aligned $\mathrm{TiO}_{2}$ nanocolumnar layers prepared by PVD-GLAD for transparent dye sensitized solar cells. Energy Environ. Sci. 4, 3426-3435. doi:10.1039/c0ee00489h

Guo, W., Liu, F., Zhu, M., Zhou, Y., and Liu, J. (2011). Microcrystalline Si nanorods by glancing angle hot wire CVD and application in organic/inorganic hybrid solar cells. Phys. Status Solidi C 8, 2810-2813. doi:10.1002/pssc.201084100

Hawkeye, M. M., and Brett, M. J. (2007). Glancing angle deposition: fabrication, properties, and applications of micro- and nanostructured thin films. J. Vac. Sci. Technol. A 25, 1317-1335. doi:10.1116/1.2764082

He, Y., Fu, J., Zhang, Y., Zhao, Y., Zhang, L., Xia, A., et al. (2007a). Multilayered Si/Ni nanosprings and their magnetic properties. Small 3, 153-160. doi:10.1002/smll.200600375

He, Y. P., Wu, J. S., and Zhao, Y. P. (2007b). Designing catalytic nanomotors by dynamic shadowing growth. Nano Lett. 7, 1369-1375. doi:10.1021/ nl070461j

He, Y., Yang, B., Yang, K., Brown, C., Ramasamy, R., Wang, H., et al. (2012). Designing Si-based nanowall arrays by dynamic shadowing growth to tailor the performance of Li-ion battery anodes. J. Mater. Chem. 22, 8294-8303. doi:10.1039/c2jm00003b

He, Y. P., Fan, J. G., and Zhao, Y. P. (2010). Engineering a well-aligned compositiongraded CuSi nanorod array by an oblique angle codeposition technique. Cryst. Growth Des. 10, 4954-4958. doi:10.1021/cg101036m

He, Y., Zhao, Y., Huang, L., Wang, H., and Composto, R. J. (2008a). Hydrogenation of $\mathrm{Mg}$ film and $\mathrm{Mg}$ nanoblade array on Ti coated Si substrates. Appl. Phys. Lett. 93, 163114. doi:10.1063/1.3003880

He, Y. P., Zhang, Z. Y., Hoffmann, C., and Zhao, Y. P. (2008b). Embedding Ag nanoparticles into $\mathrm{MgF}_{2}$ nanorod arrays. Adv. Funct. Mater. 18, 1676-1684. doi:10.1002/adfm.200800065

He, Y. P., Zhao, Y. P., and Wu, J. S. (2008c). The effect of Ti doping on the growth of Mg nanostructures by oblique angle codeposition. Appl. Phys. Lett. 92, 063107. doi:10.1063/1.2844852

He, Y.-P., and Zhao, Y.-P. (2009a). Improved hydrogen storage properties of a V decorated Mg nanoblade array. Phys. Chem. Chem. Phys. 11, 255-258. doi:10.1039/b815924f

He, Y., and Zhao, Y.-P. (2009b). Hydrogen storage and cycling properties of a vanadium decorated $\mathrm{Mg}$ nanoblade array on a Ti coated Si substrate. Nanotechnology 20, 204008. doi:10.1088/0957-4484/20/20/204008

He, Y.-P., and Zhao, Y.-P. (2011). Advanced multi-component nanostructures designed by dynamic shadowing growth. Nanoscale 3, 2361-2375. doi:10.1039/ clnr10103j

Hirvonen, J. K. (1991). Ion-beam assisted thin-film deposition. Mater. Sci. Rep. 6 , 215-274. doi:10.1016/0920-2307(91)90008-b

Huot, J., Liang, G., Boily, S., Van Neste, A., and Schulz, R. (1999). Structural study and hydrogen sorption kinetics of ball-milled magnesium hydride. J. Alloys Comp. 293, 495-500. doi:10.1016/S0925-8388(99)00474-0

Jain, I. P., Vashistha, M., Sharma, P., Devi, B., and Vijay, Y. K. (2000). “Activation energy of obliquely deposited $\mathrm{MmNi}(4.5) \mathrm{Al}(0.5)$ and $\mathrm{MmNi}(4.5) \mathrm{Al}(0.5) \mathrm{H}(\mathrm{x})$ thin films," in Hydrogen Energy Progress Xiii, Vol 1 and 2. eds Z. Q. Mao and T. N. Veziroglu. 1211-1215.

Jain, I. P., Vashistha, M., Sharma, P., Jain, R. K., and Devi, B. (2008). Activation energy of obliquely deposited $\mathrm{MmNi}(4.5) \mathrm{Al}(0.5)$ and $\operatorname{MmNi}(4.5) \mathrm{Al}(0.5) \mathrm{H}(\mathrm{x})$ thin films. Int. J. Hydrogen Energy 33, 408-412. doi:10.1016/j.ijhydene.2007.12.027

Kariuki, N. N., Khudhayer, W. J., Karabacak, T., and Myers, D. J. (2013). GLAD Pt-Ni alloy nanorods for oxygen reduction reaction. ACS Catal. 3, 3123-3132. doi:10.1021/cs400759u

Khudhayer, W. J., Kariuki, N., Myers, D. J., Shaikh, A. U., and Karabacak, T. (2012). GLAD Cr nanorods coated with SAD Pt thin film for oxygen reduction reaction. J. Electrochem. Soc. 159, B729-B736. doi:10.1149/2.087206jes

Khudhayer, W. J., Shaikh, A. U., and Karabacak, T. (2011). Platinum nanorod arrays with preferred morphological and crystal properties for oxygen reduction reaction. Adv. Sci. Lett. 4, 3551-3559. doi:10.1166/asl.2011.1867

Kiema, G. K., and Brett, M. J. (2004). Effect of thermal annealing on structural properties and electrochemical performance of carbon films with porous microstructure. J. Electrochem. Soc. 151, E194-E198. doi:10.1149/1.1695532

Kiema, G. K., Colgan, M. J., and Brett, M. J. (2005). Dye sensitized solar cells incorporating obliquely deposited titanium oxide layers. Sol. Energy Mater. Sol. Cells 85, 321-331. doi:10.1016/j.solmat.2004.05.001 
Krause, K. M., Taschuk, M. T., and Brett, M. J. (2013). Glancing angle deposition on a roll: towards high-throughput nanostructured thin films. J. Vac. Sci. Technol. A 31, 031507. doi:10.1116/1.4798947

Krishnan, R., Lu, T. M., and Koratkar, N. (2011). Functionally strain-graded nanoscoops for high power Li-ion battery anodes. Nano Lett. 11, 377-384. doi:10.1021/nl102981d

Krug, J., and Meakin, P. (1993). Scaling properties of the shadowing model for sputtering deposition. Phys. Rev. E 47, R17-R20. doi:10.1103/PhysRevE.47. R17

Larsen, G. K., Fitzmorris, B. C., Longo, C., Zhang, J. Z., and Zhao, Y. (2012). Nanostructured homogenous $\mathrm{CdSe}-\mathrm{TiO}_{2}$ composite visible light photoanodes fabricated by oblique angle codeposition. J. Mater. Chem. 22, 14205-14218. doi:10.1039/c2jm32551a

Larsen, G. K., Fitzmorris, R., Zhang, J. Z., and Zhao, Y. (2011). Structural, optical, and photocatalytic properties of $\mathrm{Cr}: \mathrm{TiO} 2$ nanorod array fabricated by oblique angle codeposition. J. Phys. Chem. C 115, 16892-16903. doi:10.1021/ jp205197f

Li, N., and Forrest, S. R. (2009). Tilted bulk heterojunction organic photovoltaic cells grown by oblique angle deposition. Appl. Phys. Lett. 95, 123309. doi:10. $1063 / 1.3236838$

Lichter, S., and Chen, J. (1986). Model for columnar microstructure of thin solid films. Phys. Rev. Lett. 56, 1396-1399. doi:10.1103/PhysRevLett.56.1396

Lin, Y. M., Abel, P. R., Flaherty, D. W., Wu, J., Stevenson, K. J., Heller, A., et al. (2011). Morphology dependence of the lithium storage capability and rate performance of amorphous $\mathrm{TiO}_{2}$ electrodes. J. Phys. Chem. C 115, 2585-2591. doi:10.1021/jp110474y

Lintymer, J., Gavoille, J., Martin, N., and Takadoum, J. (2003). Glancing angle deposition to modify microstructure and properties of sputter deposited chromium thin films. Surf. Coat. Technol. 174, 316-323. doi:10.1016/s02578972(03)00413-4

Liu, Y., Chen, L., Lu, T. M., and Wang, G. C. (2011). Low-temperature cycling of hydrogenation-dehydrogenation of Pd-decorated $\mathrm{Mg}$ nanoblades. Int. J. Hydrogen Energy 36, 11752-11759. doi:10.1016/j.ijhydene.2011.06.005

Liu, Y., Rzhevskii, A., Rigos, S., Xie, W. Y., Zhang, S. B., Lu, T. M., et al. (2013a). A study of Parylene coated $\mathrm{Pd} / \mathrm{Mg}$ nanoblades for reversible hydrogen storage. Int. J. Hydrogen Energy 38, 5019-5029. doi:10.1016/j.ijhydene.2013.02.007

Liu, Y., Zhang, F. J., and Wang, J. (2013b). Organic photovoltaic cells based on PbPc nanocolumns prepared by glancing angle deposition. Int. J. Photoenergy. 2013, 346818. doi:10.1155/2013/346818

Liu, Y., and Wang, G. C. (2012). Air stability of low-temperature dehydrogenation of Pd-decorated Mg blades. Nanotechnology 23, 025401. doi:10.1088/0957-4484/ 23/2/025401

Ma, Y., Liu, F., Zhu, M., and Zhang, Z. (2010a). Aligned microcrystalline silicon nanorods prepared by glancing angle hotwire chemical vapor deposition for photovoltaic applications. Phys. Status Solidi C 7, 537-540. doi:10.1002/pssc. 200982854

Ma, Y. H., Liu, F. Z., Zhu, M. F., and Zhang, Z. J. (2010b). Aligned microcrystalline silicon nanorods prepared by glancing angle hotwire chemical vapor deposition for photovoltaic applications. Phys. Status Solidi C 7, 537-540. doi:10.1002/pssc.200982854

Manova, D., Gerlach, J. W., and Maendl, S. (2010). Thin film deposition using energetic ions. Materials 3, 4109-4141. doi:10.3390/ma3084109

Messier, R., Venugopal, V. C., and Sunal, P. D. (2000). Origin and evolution of sculptured thin films. J. Vac. Sci. Technol. A 18, 1538-1545. doi:10.1116/1.582381

Mohan, S., and Krishna, M. G. (1995). A review of ion-beam-assisted deposition of optical thin-films. Vacuum 46, 645-659. doi:10.1016/0042-207x(95)00001-1

Monteiro, O. R. (2001). Thin film synthesis by energetic condensation. Annu. Rev. Mater. Res. 31, 111-137. doi:10.1146/annurev.matsci.31.1.111

Motohiro, T., and Taga, Y. (1989). Thin-film retardation plate by oblique deposition. Appl. Opt. 28, 2466-2482. doi:10.1364/AO.28.002466

Patzig, C., and Rauschenbach, B. (2008). Temperature effect on the glancing angle deposition of Si scalptured thin films. J. Vac. Sci. Technol. A 26, 881. doi: $10.1116 / 1.2834684$

Popok, V. N. (2011). Energetic cluster ion beams: modification of surfaces and shallow layers. Mater. Sci. Eng. R Rep. 72, 137-157. doi:10.1016/j.mser.2011.03. 001

Poxson, D. J., Kuo, M. L., Mont, F. W., Kim, Y. S., Yan, X., Welser, R. E., et al. (2011). High-performance antireflection coatings utilizing nanoporous layers. MRS Bull. 36, 434-438. doi:10.1557/mrs.2011.110
Poxson, D. J., Schubert, M. F., Mont, F. W., Schubert, E. F., and Kim, J. K. (2009). Broadband omnidirectional antireflection coatings optimized by genetic algorithm. Opt. Lett. 34, 728-730. doi:10.1364/OL.34.000728

Rider, D. A., Tucker, R. T., Worfolk, B. J., Krause, K. M., Lalany, A., Brett, M. J., et al. (2011). Indium tin oxide nanopillar electrodes in polymer/fullerene solar cells. Nanotechnology 22, 085706. doi:10.1088/0957-4484/22/8/085706

Robbie, K., Beydaghyan, G., Brown, T., Dean, C., Adams, J., and Buzea, C. (2004). Ultrahigh vacuum glancing angle deposition system for thin films with controlled three-dimensional nanoscale structure. Rev. Sci. Instrum. 75, 1089-1097. doi:10.1063/1.1667254

Robbie, K., and Brett, M. J. (1997). Sculptured thin films and glancing angle deposition: growth mechanics and applications. J. Vac. Sci. Technol. A 15, 1460-1465. doi:10.1116/1.580562

Robbie, K., Sit, J. C., and Brett, M. J. (1998). Advanced techniques for glancing angle deposition. J. Vac. Sci. Technol. B 16, 1115-1122. doi:10.1116/1.590019

Roland, C., and Guo, H. (1991). Interface growth with a shadow instability. Phys. Rev. Lett. 66, 2104. doi:10.1103/PhysRevLett.66.2104

Schubert, E., Fahlteich, J., Rauschenbach, B., Schubert, M., Lorenz, M., Grundmann, M., et al. (2006). Recrystallization behavior in chiral sculptured thin films from silicon. J. Appl. Phys. 100, 016107. doi:10.1063/1.2207728

Sharma, S. K., Kim, M. S., Kim, D. Y., and Yu, J. S. (2013). Al nanorod thin films as anode electrode for Li ion rechargeable batteries. Electrochim. Acta 87, 872-879. doi:10.1016/j.electacta.2012.09.028

Singh, M., Kulsherstha, V., Kumar, A., Acharaya, N. K., and Vijay, Y. K. (2007). The kinetics of Cr layer coated on TiNi films for hydrogen absorption. Pramana 68 , 75-81. doi:10.1007/s12043-007-0008-6

Sit, J. C., Vick, D., Robbie, K., and Brett, M. J. (1999). Thin film microstructure control using glancing angle deposition by sputtering. J. Mater. Res. 14, 1197-1199. doi:10.1557/jmr.1999.0162

Smith, W., Wolcott, A., Fitzmorris, R. C., Zhang, J. Z., and Zhao, Y. (2011). Quasicore-shell $\mathrm{TiO} 2 / \mathrm{WO} 3$ and $\mathrm{WO} 3 / \mathrm{TiO} 2$ nanorod arrays fabricated by glancing angle deposition for solar water splitting. J. Mater. Chem. 21, 10792-10800. doi:10.1039/cljm11629k

Smith, W., and Zhao, Y. P. (2009). Superior photocatalytic performance by vertically aligned core-shell TiO2/WO3 nanorod arrays. Catal. Commun. 10, 1117-1121. doi:10.1016/j.catcom.2009.01.010

Sorge, J. B., and Brett, M. J. (2010). Film morphology modification in ion-assisted glancing angle deposition. Thin Solid Films 519, 1356-1360. doi:10.1016/j.tsf. 2010.09.054

Sorge, J. B., Taschuk, M. T., Wakefield, N. G., Sit, J. C., and Brett, M. J. (2012). Metal oxide morphology in argon-assisted glancing angle deposition. J. Vac. Sci. Technol. A 30, 021507. doi:10.1116/1.3687204

Steele, J. J., and Brett, M. J. (2007). Nanostructure engineering in porous columnar thin films: recent advances. J. Mater. Sci. Mater. Electron. 18, 367-379. doi:10.1007/s10854-006-9049-8

Suzuki, M., Hamachi, K., Hara, H., Nakajima, K., Kimura, K., Hsu, C. W., et al. (2011). Vapor-liquid-solid growth of Ge nanowhiskers enhanced by hightemperature glancing angle deposition. Appl. Phys. Lett. 99, 133103. doi:10.1063/ 1.3664777

Suzuki, M., Nagai, K., Kinoshita, S., Nakajima, K., Kimura, K., Okano, T., et al. (2006). Vapor phase growth of Al whiskers induced by glancing angle deposition at high temperature. Appl. Phys. Lett. 89, 223107. doi:10.1063/1.2357582

Takagi, H., Yamada, I., and Sasaki, A. (1975). Ionized-cluster beam deposition. J. Vac. Sci. Technol. 12, 1128-1134. doi:10.1116/1.568474

Takagi, T. (1982). Role of ions in ion-based film formation. Thin Solid Films 92, 1-17. doi:10.1016/0040-6090(82)90183-3

Tang, F., Parker, T., Li, H. F., Wang, G. C., and Lu, T. M. (2007). Unusual magnesium crystalline nanoblades grown by oblique angle vapor deposition. J. Nanosci. Nanotechnol. 7, 3239-3244. doi:10.1166/jnn.2007.665

Taschuk, M. T., Tucker, R. T., Laforge, J. M., Beaudry, A. L., Kupsta, M. R., and Brett, M. J. (2013). Towards engineered branch placement: Unreal (TM) match between vapour-liquid-solid glancing angle deposition nanowire growth and simulation. J. Appl. Phys. 114, 244304. doi:10.1063/1.4854535

Teki, R., Datta, M. K., Krishnan, R., Parker, T. C., Lu, T. M., Kumta, P. N., et al. (2009). Nanostructured silicon anodes for lithium ion rechargeable batteries. Small 5, 2236-2242. doi:10.1002/smll.200900382

Thomas, M., Li, W., Bo, Z. S., and Brett, M. J. (2012). Inverted photovoltaic cells of nanocolumnar C-60 filled with solution processed small molecule 3-Q. Org. Electron. 13, 2647-2652. doi:10.1016/j.orgel.2012.07.039 
Thomas, M., Worfolk, B. J., Rider, D. A., Taschuk, M. T., Buriak, J. M., and Brett, M. J. (2011). C-60 Fullerene nanocolumns-polythiophene heterojunctions for inverted organic photovoltaic cells. ACS Appl. Mater. Interfaces 3, 1887-1894. doi:10.1021/am200076m

Van Dijken, J. G., Fleischauer, M. D., and Brett, M. J. (2011). Controlled nanostructuring of $\mathrm{CuPc}$ thin films via glancing angle deposition for idealized organic photovoltaic architectures. J. Mater. Chem. 21, 1013-1019. doi:10.1039/c0jm03026k

Vick, D., Tsui, Y. Y., Brett, M. J., and Fedosejevs, R. (1999). Production of porous carbon thin films by pulsed laser deposition. Thin Solid Films 350, 49-52. doi:10.1016/s0040-6090(99)00274-6

Wolcott, A., Smith, W. A., Kuykendall, T. R., Zhao, Y., and Zhang, J. Z. (2009). Photoelectrochemical water splitting using dense and aligned $\mathrm{TiO}_{2}$ nanorod arrays. Small 5, 104-111. doi:10.1002/smll.200800902

Wong, M. S., Lee, M. F., Chen, C. L., and Huang, C. H. (2010). Vapor deposited sculptured nano-porous titania films by glancing angle deposition for efficiency enhancement in dye-sensitized solar cells. Thin Solid Films 519, 1717-1722. doi:10.1016/j.tsf.2010.06.047

Xiao, X. D., Dong, G. P., Shao, J. D., He, H. B., and Fan, Z. X. (2010). Optical and electrical properties of $\mathrm{SnO}_{2}$ :Sb thin films deposited by oblique angle deposition. Appl. Surf. Sci. 256, 1636-1640. doi:10.1016/j.apsusc.2009.09.084

Yang, B. C., Duan, H. C., Zhou, C. H., Gao, Y. L., and Yang, J. L. (2013). Ordered nanocolumn-array organic semiconductor thin films with controllable molecular orientation. Appl. Surf. Sci. 286, 104-108. doi:10.1016/j.apsusc.2013.09.028

Yang, H. Y., Lee, M. F., Huang, C. H., Lo, Y. S., Chen, Y. J., and Wong, M. S. (2009) Glancing angle deposited titania films for dye-sensitized solar cells. Thin Solid Films 518, 1590-1594. doi:10.1016/j.tsf.2009.09.026

Yao, J. H., and Guo, H. (1993). Shadowing instability in three dimensions. Phys. Rev. E 47, 1007-1011. doi:10.1103/PhysRevE.47.1007

Yao, Y. C., Tsai, M. T., Hsu, H. C., She, L. W., Cheng, C. M., Chen, Y. C., et al. (2012). Use of two-dimensional nanorod arrays with slanted ITO film to enhance optical absorption for photovoltaic applications. Opt. Express 20, 3479-3489. doi:10.1364/OE.20.003479

Yoo, S. J., Jeon, T. Y., Kim, K. S., Lim, T. H., and Sung, Y. E. (2010). Multilayered Pt/Ru nanorods with controllable bimetallic sites as methanol oxidation catalysts. Phys. Chem. Chem. Phys. 12, 15240-15246. doi:10.1039/c0cp00737d

Young, N. O., and Kowal, J. (1959). Optically active fluorite films. Nature 183, 104-105. doi:10.1038/183104a0
Yu, P. C., Chang, C. H., Chiu, C. H., Yang, C. S., Yu, J. C., Kuo, H. C., et al. (2009). Efficiency enhancement of GaAs photovoltaics employing antireflective indium tin oxide nanocolumns. Adv. Mater. Weinheim 21, 1618, 153307. doi:10.1002/adma.200802563

Yu, P. C., Chang, C. H., Su, M. S., Hsu, M. H., and Wei, K. H. (2010). Embedded indium-tin-oxide nanoelectrodes for efficiency and lifetime enhancement of polymer-based solar cells. Appl. Phys. Lett. 96. doi:10.1063/1.3395395

Zhao, Y.-P., Ye, D.-X., Wang, G.-C., and Lu, T.-M. (2002a). Novel nano-column and nano-flower arrays by glancing angle deposition. Nano Lett. 2, 351-354. doi:10.1021/nl0157041

Zhao, Y.-P., Ye, D.-X., Wang, P.-I., Wang, G.-C., and Lu, T.-M. (2002b). Fabrication of Si nano-columns and Si square spirals on self-assembled monolayer colloid substrates. Int. J. Nanosci. 1, 87-97. doi:10.1142/S0219581X02000073

Zhao, Y.-P., Ye, D.-X., Wang, G.-C., and Lu, T.-M. (2003). Designing nanostructures by glancing angle deposition. SPIE Proc. 5219, 59. doi:10.1117/12.505253

Zhou, C. M., and Gall, D. (2006). The structure of Ta nanopillars grown by glancing angle deposition. Thin Solid Films 515, 1223-1227. doi:10.1016/j.tsf.2006.07.136

Zhou, C. M., Li, H. F., and Gall, D. (2008). Multi-component nanostructure design by atomic shadowing. Thin Solid Films 517, 1214-1218. doi:10.1039/clnr10103j

Conflict of Interest Statement: The author declares that the research was conducted in the absence of any commercial or financial relationships that could be construed as a potential conflict of interest.

Received: 14 July 2014; accepted: 10 September 2014; published online: 24 September 2014.

Citation: Zhao Y (2014) Dynamic shadowing growth and its energy applications. Front. Energy Res. 2:38. doi: 10.3389/fenrg.2014.00038

This article was submitted to Nanoenergy Technologies and Materials, a section of the journal Frontiers in Energy Research.

Copyright $(2014$ Zhao. This is an open-access article distributed under the terms of the Creative Commons Attribution License (CC BY). The use, distribution or reproduction in other forums is permitted, provided the original author(s) or licensor are credited and that the original publication in this journal is cited, in accordance with accepted academic practice. No use, distribution or reproduction is permitted which does not comply with these terms. 